\title{
Clinical and Biochemical Profiles of Filipino Patients with Distal Urea Cycle Disorders Detected by Abnormal Expanded Newborn Screening
}

\author{
Michelle E. Abadingo, ${ }^{1,2}$ Mary Ann R. Abacan, ${ }^{1,2}$ Mary Anne D. Chiong ${ }^{1,2}$ and Leniza G. De Castro-Hamoy ${ }^{1,2}$ \\ ${ }^{1}$ Division of Clinical Genetics, Department of Pediatrics, College of Medicine and Philippine General Hospital, University of the Philippines Manila \\ ${ }^{2}$ Institute of Human Genetics, National Institutes of Health, University of the Philippines, Manila
}

\begin{abstract}
Objective. The study is a retrospective review which provides preliminary data on the correlation between biochemical profiles and initial clinical manifestation of patients diagnosed to have argininosuccinate synthetase deficiency (ASSD) and argininosuccinate lyase deficiency (ASLD) detected by expanded newborn screening (ENBS).

Methods. This is a study of five distal UCD patients initially detected by elevated citrulline on ENBS. Medical charts of the patients were reviewed. The initial clinical manifestations of the patients were correlated with results of biochemical tests.
\end{abstract}

Results. There were four cases of ASLD and one case of ASSD reviewed in this study. All cases of ASLD were confirmed by the presence of argininosuccinic acid (ASA) in the urine metabolic screen (UMS). The plasma citrulline level of the ASSD patient is significantly elevated as compared to the ASLD patients $(2,690 \mu \mathrm{mol} / \mathrm{L}$; NV: 10-45 $\mu \mathrm{mol} / \mathrm{L})$. The ASSD patient and one ASLD patient were symptomatic within the first six days of life. Both presented with significantly elevated plasma ammonia, citrulline and glutamine levels. Three ASLD patients were asymptomatic on initial screening.

Conclusion. ENBS has shown importance in the early detection and management of ASSD and ASLD. Early initiation of management may prevent hyperammonemic crises. Long term outcome studies are needed to look into the correlation of neurodevelopmental outcome with lifelong accumulation of citrulline and glutamine in ASSD and ASA in ASLD.

Key Words: expanded newborn screening (ENBS), argininosuccinate synthetase deficiency (ASSD), argininosuccinate lyase deficiency (ASLD), argininosuccinic acid (ASA)

\section{INTRODUCTION}

Urea cycle disorders (UCD) comprise a rare group of inborn error of metabolism resulting from a defect in the nitrogen waste-disposal system responsible for the conversion of ammonia to urea. ${ }^{1}$ Defects in this pathway result in hyperammonemia that will result into neurologic sequelae. ${ }^{1,2,3}$ Acute hyperammonemia presents with encephalopathy that

Paper presented as poster at the $13^{\text {th }}$ Asia-Pacific Conference on Human Genetics, November 7-9, 2019, Makati Shangri-La Manila, Philippines.

Corresponding author: Michelle E. Abadingo, MD

Division of Clinical Genetics

Department of Pediatrics

Philippine General Hospital

University of the Philippines Manila

Taft Avenue, Manila 1000, Philippines

Email: meabadingo@up.edu.ph may progress to brain edema and death. ${ }^{4}$ In a multicenter study of UCD patients, it was found that intellectual and developmental disabilities were reported the most, followed by learning disability. ${ }^{5}$

Urea cycle disorders may be categorized as either proximal or distal (Figure 1). Proximal UCDs is the absence or lack of mitochondrial enzymes involved in the cycle. Distal UCDs, on the other hand, is the deficiency of cytosolic enzymes involved in the urea cycle. This includes 


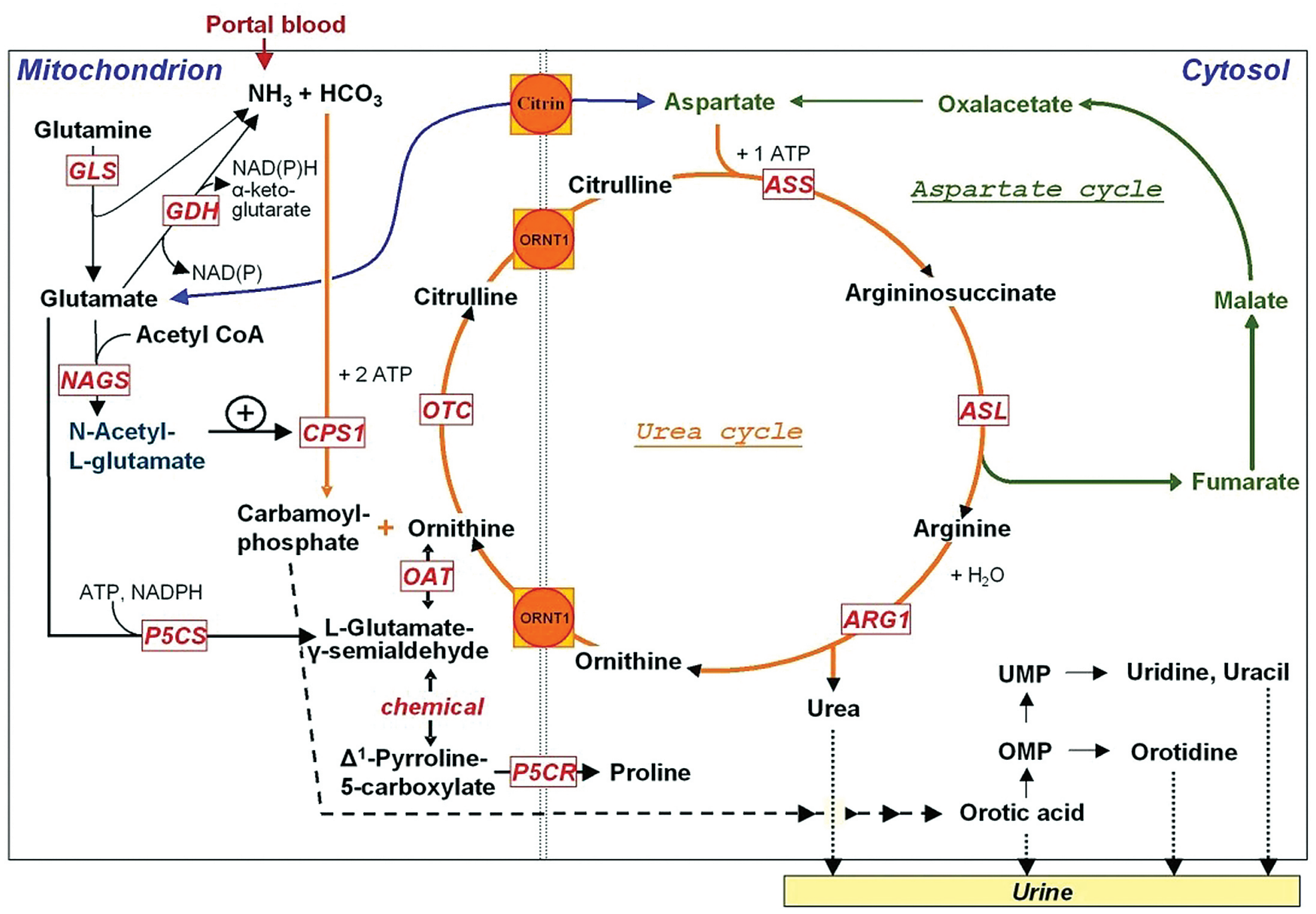

Figure 1. The urea cycle and associated pathways. Urea cycle disorders (UCDs) result from inherited deficiency in any one of the six enzymes or transporters of the urea cycle pathway. Proximal UCDs is the lack or absence of mitochondrial enzymes. This include $\mathrm{N}$-acetyl-L-glutamate synthetase (NAGS), carbamoylphosphate synthetase 1 (CPS1), and ornithine transcarbomylase (OTC). Distal UCDs, on the other hand, is the lack or absence of enzymes in the cytosol. This include argininosuccinate synthetase (ASS), argininosuccinate lyase (ASL) and arginase 1 (ARG1). In an enzyme deficiency, there is an increase in the metabolite proximal to the enzyme.

Figure reprinted from Häberle J, Boddaert N, Burlina A, Chakrapani A, Dixon M, Huemer M, et al. Suggested guidelines for the diagnosis and management of urea cycle disorders. Orphanet J Rare Dis. 2012 May; 7:32. Article distributed under the terms of the Creative Commons Attribution License (http://creativecommons.org/licenses/by/2.0).

argininosuccinate synthetase deficiency (ASSD) (OMIM \#603470) and argininosuccinate lyase deficiency (ASLD) (OMIM \#608310). Studies have shown that patients with ASSD and ASLD are equally or more severely impaired as compared to the proximal UCDs. In the case of ASLD, the clinical phenotype appears to be unrelated to the severity and duration of hyperammonemic episodes. ${ }^{6,7}$

Prior to 2014, the newborn screening panel in the Philippines was limited to six disorders - congenital hypothyroidism $(\mathrm{CH})$, congenital adrenal hyperplasia $(\mathrm{CAH})$, phenylketonuria (PKU), glucose-6-phosphate dehydrogenase deficiency (G6PD) and maple syrup urine disease (MSUD). ${ }^{8}$ Expanded newborn screening (ENBS) has been available in the Philippines since 2014 and has allowed screening for 28 disorders. ASSD was the first urea cycle disorder included in the panel ${ }^{9}$ Citrulline is used as a primary marker for ASSD and ASLD in Tandem Mass Spectrometry. ${ }^{10,11,12}$ ASLD was recently included in the ENBS panel of the Philippines.

In the study by Padilla and de la Paz, ${ }^{13}$ there was one ASLD patient in the metabolic registry of the Biochemistry laboratory, Institute of Human Genetics. This patient was diagnosed before 2014, the year ENBS was initiated. Currently, there are five ASLD patients and one ASSD patient in the registry (Personal communication, Biochemistry laboratory). In the Philippine setting, plasma amino acid profile and comprehensive urine metabolic screen (UMS) are done to confirm a UCD diagnosis. The presence of argininosuccinic acid (ASA) in the UMS is the biochemical hallmark of ASLD. ${ }^{7,14}$ On the other hand, plasma amino acid levels of patients with ASSD reveal an ammonia of $\geq 1,000 \mu \mathrm{mol} / \mathrm{L}$, glutamine $>1,000 \mu \mathrm{mol} / \mathrm{L}$ and citrulline often $>2,000 \mu \mathrm{mol} / \mathrm{L} ., 15$ 
Table 1. Summary of biochemical findings of patients diagnosed with distal urea cycle disorders

\begin{tabular}{|c|c|c|c|c|c|c|}
\hline \multirow[b]{2}{*}{ Patient number } & \multirow{2}{*}{$\begin{array}{l}\text { ENBS Collection } \\
\text { (Day of life) }\end{array}$} & \multicolumn{4}{|c|}{ Expanded Newborn Screening } & \multirow{2}{*}{$\begin{array}{c}\text { Plasma Ammonia } \\
\mu \mathrm{mol} / \mathrm{L}\end{array}$} \\
\hline & & $\begin{array}{c}\text { Citr } \\
\mu \mathrm{mol} / \mathrm{L}\end{array}$ & Citr/Phe & Citr/Arg & Citr/Tyr & \\
\hline 1 & 1 & 84.3 & 1.48 & NA & $1(\leq 0.45)$ & 53 \\
\hline 2 & 4 & 87.25 & 1.76 & 8.5 & NA & 31 \\
\hline 3 & 6 & 186.12 & 6.32 & 21.31 & NA & 500 \\
\hline 4 & 1 & 74.4 & 1.37 & 5.93 & NA & 94 \\
\hline 5 & 5 & $3,123.49$ & 38.47 & 243.83 & NA & 745 \\
\hline Reference value & & $<60$ & $<1.1$ & $<19.61$ & $\leq 0.45$ & 9 to 33 \\
\hline Mean & 3.4 & 711.11 & 9.88 & 69.89 & & 284.6 \\
\hline Standard Deviation & 2.30 & 1349.32 & 16.12 & 116.15 & & 321.19 \\
\hline
\end{tabular}

${ }^{*}$ Reference range values for plasma amino acid for age group 31 days to 23 months. Sample was taken on the $33^{\text {rd }}$ day of life.

The Urea Cycle Disorders longitudinal study, a multicenter investigation, has shown that $25 \%$ of ASSD was detected by ENBS as compared to $29 \%$ of ASLD. ${ }^{16} \mathrm{~A}$ 27-year follow up study done in Austria showed a favorable outcome of ASLD patients identified by NBS. Patients were asymptomatic until 4 weeks of life or later when diagnosis and treatment was initiated. ${ }^{17}$ In another study done in Massachusetts, 13 patients diagnosed to have ASLD by newborn screening had a relatively mild clinical course due to early diagnosis and treatment. ${ }^{18}$

This study reviewed the clinical and biochemical profile of Filipino patients diagnosed to have argininosuccinate synthetase deficiency (ASSD) and argininosuccinate lyase deficiency (ASLD) detected by ENBS and confirmed by biochemical investigations. This can be used as preliminary data on the correlation between biochemical findings and initial clinical manifestations of the two mentioned disorders in the Filipino population.

\section{METHODS}

\section{Description of Study Setting}

The Institute of Human Genetics, National Institutes of Health (IHG-NIH), University of the Philippines, Manila is the unit that co-manages and receives referrals from the different newborn screening centers. Cases were identified from the records of confirmed cases of the Biochemistry Laboratory, IHG-NIH.

\section{Subjects}

This study involved a chart review of five Filipino patients confirmed to have argininosuccinate synthetase deficiency (ASSD) and argininosuccinate lyase deficiency (ASLD) from December 2014 to September 2018. The diagnosis was based on elevated citrulline in ENBS and confirmed by plasma and urine amino acids and urine organic acid. This study was reviewed and approved by the University of the Philippines Manila Research Ethics Board (UPMREB Number 2018-459-01).

\section{Clinical and Biochemical Characteristics}

Data on the patient's date of birth, day of collection of samples for ENBS and initial presenting symptoms were obtained from the Clinical Genetics Unit, IHG-NIH and records of attending metabolic specialist and clinical geneticist. Initial plasma ammonia, plasma amino acid profile, urine organic acid, and/or UMS were reviewed. For all patients, results of the plasma amino acid and UMS were obtained from the Biochemistry laboratory, IHG-NIH.

Clinical and biochemical data collected were transferred in a password-protected Microsoft Excel (Microsoft Corporation, Redmond, WA, USA) spreadsheet file. Mean and standard deviation were obtained for the plasma ammonia and plasma amino acid values.

\section{RESULTS}

\section{Demographic and Biochemical Findings}

There were five patients diagnosed to have a distal urea cycle disorder through ENBS: one argininosuccinate synthetase deficiency (ASSD) and four argininosuccinate lyase deficiency (ASLD). The five patients were distributed in the islands of Luzon and Visayas. The case of ASSD was from Guimaras, an island in Western Visayas. Three of the ASLD patients were from Luzon (one from Ilocos Norte, one from Bulacan and one from Manila). The fourth ASLD patient was from Capiz, a province in Visayas.

Table 1 shows the biochemical findings of the five patients with distal UCD. ENBS was done on an average of 3.4 days (range one to six days). In two patients, 6-test newborn screening (NBS) was initially done which yielded normal results. ENBS was only done when they already presented with signs and symptoms of UCD. The patients' citrulline levels on ENBS ranged from 74.4 to 3,123.49 $(\mathrm{NV}<60 \mu \mathrm{mol} / \mathrm{L})$. All patients had elevations in at least one secondary analyte (citrulline/phenylalanine ratio). Three patients had elevations in secondary analytes (citrulline/ phenylalanine and citrulline/arginine ratios). 


\begin{tabular}{|c|c|c|c|c|c|}
\hline \multicolumn{4}{|c|}{ Plasma Amino Acid } & \multirow[b]{2}{*}{ Urine Metabolic Screen } & \multirow[b]{2}{*}{ Diagnosis } \\
\hline $\begin{array}{l}\text { Citrulline } \\
\mu \mathrm{mol} / \mathrm{L}\end{array}$ & $\begin{array}{l}\text { Arginine } \\
\mu \mathrm{mol} / \mathrm{L}\end{array}$ & $\begin{array}{l}\text { Ornithine } \\
\mu \mathrm{mol} / \mathrm{L}\end{array}$ & $\begin{array}{l}\text { Glutamine } \\
\mu \mathrm{mol} / \mathrm{L}\end{array}$ & & \\
\hline 235 & 15 & 13 & 693 & Argininosuccinic acid and anhydrides & ASLD \\
\hline $95^{*}$ & $43^{*}$ & $63^{*}$ & $397^{*}$ & Argininosuccinic acid and anhydrides & ASLD \\
\hline \multirow[t]{2}{*}{115} & 16 & 18 & 1120 & Argininosuccinic acid and anhydrides & ASLD \\
\hline & & & & Argininosuccinic acid and anhydrides & ASLD \\
\hline 2690 & 28 & 24 & 1917 & $\begin{array}{l}\text { Increased intensity of bands at levels of glutamine } \\
\text { and citrulline is suggestive of citrullinemia }\end{array}$ & ASSD \\
\hline $\begin{array}{l}* 3 \text { to } 45 \\
10 \text { to } 45\end{array}$ & $\begin{array}{l}* 12 \text { to } 133 \\
6 \text { to } 140\end{array}$ & $\begin{array}{l}* 22 \text { to } 103 \\
48 \text { to } 211\end{array}$ & $\begin{array}{c}* 246 \text { to } 1182 \\
340 \text { to } 940 \\
\end{array}$ & & \\
\hline 783.75 & 25.5 & 29.5 & 1031.75 & & \\
\hline 1272.34 & 13.08 & 22.78 & 660.58 & & \\
\hline
\end{tabular}

Table 2. Summary of clinical findings of patients diagnosed with distal urea cycle disorders

\begin{tabular}{|c|c|c|c|c|c|c|c|c|c|}
\hline $\begin{array}{l}\text { Patient } \\
\text { number }\end{array}$ & Sex & $\begin{array}{l}\text { Pediatric } \\
\text { Aging }\end{array}$ & Ethnicity & Consanguinity & $\begin{array}{c}\text { Initial Clinical } \\
\text { Presentation and } \\
\text { Age of Presentation }\end{array}$ & Management & $\begin{array}{l}\text { Outcome and } \\
\text { current status }\end{array}$ & $\begin{array}{l}\text { Current } \\
\text { age }\end{array}$ & Diagnosis \\
\hline 1 & Male & 38 & Filipino & $\begin{array}{c}\text { non- } \\
\text { consanguineous } \\
\end{array}$ & Asymptomatic & $a, b, c$ & $\begin{array}{l}\text { Alive; Developmentally } \\
\text { at par }\end{array}$ & $\begin{array}{c}11 \\
\text { months }\end{array}$ & ASLD \\
\hline 2 & Male & 40 & Filipino & $\begin{array}{c}\text { non- } \\
\text { consanguineous }\end{array}$ & Asymptomatic & $a, b$ & $\begin{array}{c}\text { Alive; Developmentally } \\
\text { at par }\end{array}$ & $\begin{array}{c}9 \\
\text { months }\end{array}$ & ASLD \\
\hline 3 & Male & 38 & Filipino & $\begin{array}{c}\text { non- } \\
\text { consanguineous }\end{array}$ & $\begin{array}{l}\text { Poor feeding } \\
\text { Irritability } \\
\text { hyperthermia on } \\
\text { the } 6^{\text {th }} \text { day of life } \\
\end{array}$ & $a, d, e, f$ & $\begin{array}{c}\text { Died at } 11 \text { months for } \\
\text { metabolic decompensation } \\
\text { secondary to acute } \\
\text { gastroenteritis }\end{array}$ & & ASLD \\
\hline 4 & Male & 39 & Filipino & $\begin{array}{c}\text { non- } \\
\text { consanguineous }\end{array}$ & Asymptomatic & $a, b, c$ & $\begin{array}{l}\text { Alive; Ongoing } \\
\text { physical therapy for } \\
\text { gross motor delay }\end{array}$ & $\begin{array}{l}1 \text { year } 9 \\
\text { months }\end{array}$ & ASLD \\
\hline 5 & Male & 38 & Filipino & $\begin{array}{c}\text { non- } \\
\text { consanguineous }\end{array}$ & $\begin{array}{l}\text { Poor feeding } \\
\text { Increased sleeping } \\
\text { time on the } 5^{\text {th }} \\
\text { day of life }\end{array}$ & $d^{*}$ & $\begin{array}{l}\text { Died during the } \\
\text { neonatal period }\end{array}$ & & ASSD \\
\hline
\end{tabular}

$a$ - Protein limitation; $b$ - Oral sodium benzoate; c - Oral L-arginine; $d$ - High dextrosity fluid and/or lipid emulsion; $e$ - Intravenous sodium benzoate; $f$ - Intravenous L-arginine. ${ }^{*}$ - Peritoneal dialysis, protein limitation, intravenous sodium benzoate and L-arginine were recommended for the patient.

Initial plasma ammonia levels for the patients ranged from 31-745 $\mu \mathrm{mol} / \mathrm{L}(\mathrm{NV}: 9-33 \mu \mathrm{mol} / \mathrm{L})$. Citrulline levels were elevated for four patients, with an average level of 783.75 $\mu \mathrm{mol} / \mathrm{L}$ (Range: $95-2,690 \mu \mathrm{mol} / \mathrm{L} ; \mathrm{NV}: 10-45 \mu \mathrm{mol} / \mathrm{L}$ ). The citrulline of the patient with ASSD is significantly elevated at 2,690 $\mu \mathrm{mo} / \mathrm{L}$. Glutamine values were also elevated for patients 3 and 5. Patient 5 had the highest glutamine value of $1,917 \mu \mathrm{mol} / \mathrm{L}(\mathrm{NV}: 340-910 \mu \mathrm{mol} / \mathrm{L})$. Ornithine and arginine levels were within reference range values; with average values of $25.5 \mu \mathrm{mol} / \mathrm{L}(\mathrm{NV}: 48-210 \mu \mathrm{mol} / \mathrm{L})$ and $29.5 \mu \mathrm{mol} / \mathrm{L}(\mathrm{NV}: 6-140 \mu \mathrm{mol} / \mathrm{L})$, respectively.

Comprehensive urine amino and organic acid profiles are part of the confirmatory test for urea cycle disorders. Patient 5, a case of ASSD, showed presence of orotic acid in urine organic acid analysis. The four patients with ASLD had non-specific findings. For all patients, urine amino acids were analyzed by high volume electrophoresis. The presence of ASA and its anhydrides confirmed the diagnosis of ASLD in the four patients. For patient 5, increased intensity of bands at levels of glutamine and citrulline was suggestive of the diagnosis. This was consistent with the patient's elevated plasma citrulline and glutamine levels.

\section{Clinical Presentation}

Table 2 shows the clinical presentation of patients with distal UCD. All patients in this study were males. All were full-term and were born to non-consanguineous unions of Filipino descent. Patient 3 and patient 5 were symptomatic within the first six days of life with elevated plasma ammonia at $500 \mu \mathrm{mol} / \mathrm{L}$ and $745 \mu \mathrm{mol} / \mathrm{L}$, respectively. Patient 3 presented with poor feeding, irritability and hyperthermia on the $6^{\text {th }}$ day of life. Patient 5 , on the other hand, exhibited poor feeding and increased sleeping time on the $5^{\text {th }}$ day of life.

Medical management for acute metabolic decompensation was initiated for patient 3, a case of ASLD. This included initially placing the patient on protein rest and 
increasing total caloric intake. Total caloric intake was increased with high dextrosity intravenous fluid and lipid emulsion. Patient was also started on intravenous sodium benzoate and L-arginine. He was discharged after 31 hospital days. Medical management and peritoneal dialysis were recommended for patient 5 on the basis of significantly elevated plasma ammonia level and deteriorating clinical status. However, caregivers opted to bring the patient home instead. The patient died during the neonatal period.

Patients 1,2 and 4 were asymptomatic on initial referral. Initial plasma ammonia values of the 3 patients ranged from 31-94 $\mu \mathrm{mol} / \mathrm{L}$ (NV: 9-33 $\mu \mathrm{mol} / \mathrm{L})$. Medical management for urea cycle disorder was initiated on outpatient basis. Initial management included protein restriction at 1-1.5 $\mathrm{mg} / \mathrm{kg} /$ day. L-arginine was started at $92-100 \mathrm{mg} / \mathrm{kg} / \mathrm{dose}$. For patients 1 and 4, sodium benzoate was initiated at 100 $\mathrm{mg} / \mathrm{kg} /$ day. Patients 1 and 2 are on regular follow-up with the metabolic service of the Philippine General Hospital (UP-PGH). Patient 4 is on regular follow up with a metabolic specialist. The oldest living patient is now one year and nine months, while the youngest patient is nine months old. Since diagnosis, the three patients never had an episode of metabolic crisis. Despite the absence of a metabolic crisis, patient 4 is ongoing physical therapy for gross motor delay. $\mathrm{He}$ is also being seen by a Developmental Pediatrician for co-management.

\section{DISCUSSION}

This is the first review of diagnosed cases of distal urea cycle disorders initially detected by expanded newborn screening (ENBS) in the Philippines. The national coverage of ENBS in the Philippines is only $12.8 \%$ as of December, 2018. ${ }^{19}$ Since ENBS was initiated in 2014, there have been four diagnosed cases of ASLD and one diagnosed case of ASSD out of 665,578 babies screened. ${ }^{20}$

Urea cycle disorders may present as a neonatal onset or late onset form. Patients with the neonatal onset form appear normal for 24-48 hours and then exhibit non-specific signs and symptoms such as progressive lethargy, hypothermia and apnea. The signs and symptoms are related to elevated plasma ammonia levels. ${ }^{1,3}$ Ammonia toxicity is thought to cause cytotoxic brain edema and astrocyte swelling through a variety of mechanisms. ${ }^{21}$ Hyperammonemia may result into the perturbation of potassium buffering in the astrocytes, altered $\gamma$-aminobutyric acid (GABA)-mediated transmission causing excitotoxicity, and toxicity caused by oxidative stress due to increased free radical formation and increased nitric oxide synthesis. ${ }^{1,22,23,24}$

In this study, two patients presented with the neonatal onset form. Plasma ammonia level of $150 \mu \mathrm{mol} / \mathrm{L}$ or higher in neonates with associated neurologic signs and symptoms is a strong indication for the presence of a UCD. ${ }^{21}$ As compared to ASSD, hyperammonemia is usually less severe in ASLD. Argininosuccinate is freely excreted in the urine, therefore disposing 4 nitrogen molecules. ${ }^{21}$ It was also previously reported that no UCD patient having had $>300$ $\mu \mathrm{mol} / \mathrm{L}$ initial or $>480 \mu \mathrm{mol} / \mathrm{L}$ peak ammonia exhibited normal psychomotor development. ${ }^{24,25}$

Three patients (patients 1,2 and 4) were asymptomatic on initial presentation and never had an episode of metabolic decompensation. All three had an initial plasma ammonia $<150 \mu \mathrm{mol} / \mathrm{L}$ (Range: 31-94 $\mu \mathrm{mol} / \mathrm{L}$ ). Based on the patients' clinical presentation, they may have the late onset or partial enzyme deficiency form. For the late onset form, elevation in ammonia is brought about at any age by stressors, such as infection, post-operative state, and high protein diet, that overwhelms the individual's capacity to convert ammonia to urea. . $^{1,2,3,21}$

ENBS and associated biochemical tests were helpful in coming up with a diagnosis and initiating appropriate management. As with the Philippine ENBS program, ${ }^{8}$ citrulline is used as the primary metabolite for distal urea cycle disorders in other programs worldwide. ${ }^{10,11,12,26}$ As the metabolite proximal to enzymes argininosuccinate synthethase and argininosuccinate lyase, citrulline is elevated in cases of ASSD and ASLD. In ASLD, the expected range of plasma citrulline is $100-300 \mu \mathrm{mol} / \mathrm{L} .{ }^{1,14}$ However, deficiency of argininosuccinate synthetase in ASSD leads to extreme elevation of citrulline in plasma with expected range of 2,000-5,000 $\mu \mathrm{mol} / \mathrm{L} .{ }^{27}$

An increase in plasma citrulline may also induce elevation of glutamine and ammonia, depletion of arginine, and enhanced excretion of orotic acid in urine. ${ }^{3,27}$ Excretion of orotic acid in the urine was seen in patient 5 . Glutamine levels are considered tolerable when they do not exceed 1000 $\mu \mathrm{mol} / \mathrm{L} .{ }^{3}$ It can be noted that the symptomatic patients in this study had plasma glutamine levels of more than 1000 $\mu \mathrm{mol} / \mathrm{L}$. Rising plasma glutamine levels may indicate pending hyperammonemia. ${ }^{3}$

UMS has allowed the differentiation between ASSD and ASLD in our laboratory. The presence of ASA and its metabolites as an incidental finding in the UMS warranted the inclusion of ASLD in the newborn screening panel. The diagnostic criteria for ASLD is the presence of ASA in the blood or urine. ${ }^{5}$ Argininosuccinate lyase is the enzyme responsible of breaking down argininosuccinate to arginine and fumarate. ASA is not routinely detected in plasma amino acid analysis and can easily be misidentified since it may co-elute with other amino acid, especially leucine. Since ASA is markedly excreted in urine, UMS is helpful in detecting ASLD. ${ }^{28,29}$ Quantitative measurement of urine ASA may be done by column chromatography. ${ }^{17}$

Reversal of catabolic state is one of the cornerstones in the management of ASLD and ASSD. ${ }^{3,21}$ Catabolism of protein stores triggers hyperammonemia. An affected child will continue to produce ammonia and will not stabilize until catabolism is reversed. ${ }^{21}$ Catabolism is addressed by increasing the total caloric intake. Caloric supplementation include intravenous high dextrosity fluid and lipid emulsion. 
Cessation of protein intake is done for maximum of 48 hours. ${ }^{3}$ Pharmacologic intervention include administration of ammonia scavenger and L-arginine. Sodium benzoate is an ammonia scavenger that conjugates benzoate with glycine to produce hippurate; urea cycle is bypassed. ${ }^{3}$ $\mathrm{L}$-arginine, on the other hand, is used to replace arginine not produced by the urea cycle. ${ }^{21}$ Extracorporeal detoxification of ammonia is done for levels $>500 \mu \mathrm{mol} / \mathrm{L} .^{3}$ It can be done for lower ammonia levels if affected individual is grossly encephalopathic and refractory to medical therapy. ${ }^{3,21}$

ENBS has helped in the early detection and management of distal urea cycle disorders. This is particularly true for cases of late onset UCDs where neonates are asymptomatic due to partial enzyme activity. A study had shown that patients detected to have distal UCD by newborn screening have higher scores for neuropsychological tests as compared to clinically identified cases. ${ }^{30}$

Despite early intervention for distal UCD cases detected by newborn screening, gross motor delay, expressive language delay and decreased performance IQs are prominent for both ASSD and ASLD. ${ }^{17,31}$ The presence of ASA and its metabolites in ASLD has been implicated in the higher incidence of neurocognitive symptoms, liver fibrosis, renal impairment and systemic hypertension., ${ }^{714}$ This will explain the presence of gross motor delay in patient 4 despite early intervention and absence of metabolic crises. It was also noted that for both distal urea cycle disorders, cognitive impairment is present even in the absence of hyperammonemic crises.

In this study, patients were confirmed to have distal UCD through biochemical testing correlated with clinical presentation. However, mutation studies would be ideal since specific mutations are associated with the neonatal and late onset forms. ${ }^{30,32}$ While biochemical studies can establish the diagnosis of the two mentioned disorders, molecular investigations help understand the phenotypic variations and prognosis of the disease. While genetic counselling was documented for the patients, molecular investigations would had provided crucial supporting information regarding pathogenesis and outcome. ${ }^{3}$

\section{CONCLUSION}

ENBS, along with plasma amino acid profile and urine metabolic screen results, have shown importance in the early detection and management of ASSD and ASLD in the local setting. The physician should correlate the patient's clinical presentation and laboratory results to immediately start intervention. Early initiation of management may contribute in the prevention of hyperammonemic crises for late-onset cases of ASSD and ASLD. Long term studies are needed to look into the correlation of neurodevelopmental outcome with lifelong accumulation of ammonia, citrulline and glutamine in our patients with both ASLD and ASLD and ASA in ASLD. Molecular testing is recommended to help understand the phenotypic variation of the disease and its prognosis. It can also provide information needed for genetic counselling for the families affected.

\section{Statement of Authorship}

All authors have approved the final version submitted.

\section{Author Disclosure}

All authors declared no conflicts of interest.

\section{Funding Source}

This study was funded by the authors.

\section{REFERENCES}

1. Helman G, Pacheco-Colon I, Gropman AL. The urea cycle disorders. Semin Neurol. 2014 Jul; 34(3): 341-9.

2. Brusilow SW, Horwich AL. Urea cycle enzymes. In: Scriver C, Beaudet A, Sly W, Valle D, eds. Metabolic and Molecular Bases of Inherited Diseases, 7th ed. New York: McGraw-Hill; 1995. p.1187.

3. Häberle J, Boddaert N, Burlina A, Chakrapani A, Dixon M, Huemer $\mathrm{M}$, et al. Suggested guidelines for the diagnosis and management of urea cycle disorders. Orphanet J Rare Dis. 2012 May; 7:32.

4. Walker V. Ammonia toxicity and its prevention in inherited defects of the urea cycle. Diabetes Obes Metab. 2009 Sep; 11(9):823-35.

5. Tuchman M, Lee B, Lichter-Konecki U, Summar ML, Yudkoff M, Cederbaum SD, et al. Cross-sectional multicenter study of patients with urea cycle disorders in the United States. Mol Genet Metab. 2008 Aug; 94(4):397-402.

6. Ah Mew N, Krivitzsky L, McCarter R, Batshaw M, Tuchman M, Urea Cycle Disorders Consortium of the Rare Diseases Clinical Research Network. Clinical outcomes of neonatal onset proximal versus distal urea cycle disorders do not differ. J Pediatr. 2013 Feb; 162(2):324-9.

7. Naganami SCS, Erez A, B Lee. Arginosuccinate lyase deficiency. Genet Med. 2012 May; 14(5):501-7.

8. Padilla CD. Enhancing case detection of selected inherited disorders through expanded newborn screening program in the Philippines. Acta Med Philipp. 2012; 46(4):24-9.

9. Newborn Screening Reference Center. Expanded Newborn Screening Panel: Disorders Included in the Expanded NBS Panel and the Metabolites Tested [Internet]. [cited 2018 Aug 19]. Available from: https:/www.newbornscreening.ph/images/stories/ ResourcesTechnicalDocuments/enbs-panel.pdf.

10. Fernandez-Lainez C, Aguilar-Lemus JJ, Vela-Amieva M, IbarraGonzalez I. Tandem mass spectrometry newborn screening for inborn errors of intermediary metabolism: abnormal profile interpretation. Curr Med Chem. 2012; 19(26):4511-22.

11. Lehotay DC, Hall PL, Lepage J, Eichhorst JC, Etter ML, Greenberg CR. LC-MS/MS progress in newborn screening. Clin Biochem. 2011 Jan; 44(1):21-31.

12. Garg U, Dasuoki M. Expanded newborn screening of inherited metabolic disorders by tandem mass spectrometry: Clinical and laboratory aspects. Clin Biochem. 2006 Apr; 39(4):315-32.

13. Padilla CD, Cutiongco-De La Paz EM. Genetics and genomic medicine in the Philippines. Mol Genet Genomic Med. 2016 Sep; 4(5):494-503.

14. Erez A, Sreenath Nagamani SC, Lee B. Arginosuccinate lyase deficiency - arginosuccinic aciduria and beyond. Am J Med Genet C Semin Med Genet. 2011 Feb; 157C(1):45-53.

15. Diez-Fernandez C, Rufenacht V, Häberle J. Mutations in the human argininosuccinate synthetase (ASS1) gene, impact on patients, common changes and structural considerations. Hum Mutat. 2017 May; 38(5):471-84.

16. Waisbren SE, Cuthbertson D, Burgard P, Holbert A, McCarter $\mathrm{R}$, Cederbaum S, et al. Biochemical markers and neuropsychological functioning in distal urea cycle disorders. J Inherit Metab Dis. 2018 Jul; 41(4):657-67. 
17. Mercimek-Mahmutoglu S, Moeslinger D, Häberle J, Engel K, Herle M, Strobl MW, et al. Long-term outcome of patients with argininosuccinate lyase deficiency diagnosed by newborn screening in Austria. Mol Gen Metab. 2010 May; 100(1):24-8.

18. Ficicioglu C, Mandell R, Shih VE. Argininosuccinate lyase deficiency: long term outcome of 13 patients detected by newborn screening. Mol Genet Metab. 2009 Nov; 98(3):273-7.

19. Newborn Screening Reference Center. NBS Statistics [Internet]. 2018 [cited 2019 Jul 31]. Available from: https://www.newbornscreening. $\mathrm{ph} /$ images/stories/nbs-coverage-2018.jpg.

20. Newborn Screening Reference Center. Prevalence of Disorders [Internet]. 2018 [cited 2019 Jul 31]. Available from: https:// www.newbornscreening.ph/images/stories/ResourcesPrevalence/ prevalence-2018.pdf

21. Summar ML, Ah Mew N. Inborn errors of metabolism with hyperammonemia: urea cycle defects and related disorders. Pediatr Clin North Am. 2018 Apr; 65(2):231-46.

22. Lichter-Konecki U. Profiling of astrocyte properties in the hyperammonemic brain: shedding new light on the pathophysiology of brain damage in hyperammonemia. J Inherit Metab Dis. 2008 Aug; 31(4):492-502.

23. Eid T, Lee TSW. Reassessing the role of astrocytes in ammonia neurotoxicity. Nat Med. 2013 Dec; 19(12):1572-14.

24. Bachmann C. Outcome and survival of 88 patients with urea cycle disorders: a retrospective evaluation. Eur J Pediatr. 2003 Jun; 162(6):410-6.

25. Posset R, Garcia-Cazorla A, Valayannopoulos V, Teles EL, DionisiVici C, Brassier A, et al. Age at disease onset and peak ammonium level rather than interventional variables predict the neurological outcome in urea cycle disorders. J Inherit Metab Dis. 2016 Sep; 39(5):661-72.
26. Barends M, Pitt J, Morrissy S, Tzanakos N, Boneh A, Newborn Screening Laboratory Staff. Biochemical and molecular characteristics of patients with organic acidaemias and urea cycle disorders identified through newborn screening. Mol Genet Metab. 2014 Sep-Oct; 113(1-2):46-52.

27. Häberle J, Pauli S, Linneback M, Kleijer WJ, Bakker HD, Wanders RJA, et al. Structure of the human argininosuccinate synthetase gene and an improved system for molecular diagnostics in patients with classical and mild citrullinemia. Hum Genet. 2002 Apr; 110(4):327-33.

28. Chen BC, Ngu LH, Zabedah MY. Argininosuccinic aciduria. Clinical and biochemical phenotype findings in Malaysian children. Malays J Pathol. 2010 Dec; 32(2):87-95.

29. Palmer T, Oberholzer VG, Levin B, Burgess EA. Urinary excretion of argininosuccinic acid. Clin Chim Acta. 1973 Sep; 47(3):443-8.

30. Waisbren SE, Gropman AL, Batshaw ML, Members of the Urea Cycle Disorders Consortium (UCDC). Improving long term outcomes in urea cycle disorders - report from the Urea Cycle Disorders Consortium. J Inherit Metab Dis. 2016 Jul; 39(4); 573-84.

31. Balmer C, Pandey AV, Rufenacht V, Nuoffer JM, Fang P, Wong LJ, et al. Mutations and polymorphisms in the human arginosuccinate lyase (ASL) gene. Hum Mutat. 2014 Jan; 35(1):27-35.

32. Gao HZ, Kobayashi K, Tabata A, Tsuge H, Iijima M, Yasuda T, et al. Identification of 16 novel mutations in the argininosuccinate synthetase gene and genotype-phenotype correlation in 38 classical citrullinemia patients. Hum Mutat. 2003 Jul; 22(1):24-34. 